Review Article

\title{
Buccal Fat Pad as a Potential Source of Stem Cells for Bone Regeneration: A Literature Review
}

\author{
Nasim Salehi-Nik, ${ }^{1}$ Maryam Rezai Rad, ${ }^{2}$ Lida Kheiri, ${ }^{3}$ Pantea Nazeman, ${ }^{2}$ \\ Nasser Nadjmi, ${ }^{4}$ and Arash Khojasteh ${ }^{1,5,6}$ \\ ${ }^{1}$ Department of Tissue Engineering, School of Advanced Technologies in Medicine, Shahid Beheshti University of Medical Sciences, \\ Tehran, Iran \\ ${ }^{2}$ Dental Research Center, Research Institute of Dental Sciences, School of Dentistry, Shahid Beheshti University of Medical Sciences, \\ Tehran, Iran \\ ${ }^{3}$ School of Dentistry, Shahid Beheshti University of Medical Sciences, Tehran, Iran \\ ${ }^{4}$ University of Antwerp, The Team for Cleft and Craniofacial Anomalies, Oral and Maxillofacial Surgery, University of Antwerp, \\ Antwerp, Belgium \\ ${ }^{5}$ Medical Nano-Technology \& Tissue Engineering Research Center, Shahid Beheshti University of Medical Sciences, Tehran, Iran \\ ${ }^{6}$ Faculty of Medicine, University of Antwerp, Antwerp, Belgium
}

Correspondence should be addressed to Arash Khojasteh; arashkhojasteh@yahoo.com

Received 3 December 2016; Revised 17 April 2017; Accepted 16 May 2017; Published 5 July 2017

Academic Editor: Heinrich Sauer

Copyright (C) 2017 Nasim Salehi-Nik et al. This is an open access article distributed under the Creative Commons Attribution License, which permits unrestricted use, distribution, and reproduction in any medium, provided the original work is properly cited.

\begin{abstract}
Adipose tissues hold great promise in bone tissue engineering since they are available in large quantities as a waste material. The buccal fat pad (BFP) is a specialized adipose tissue that is easy to harvest and contains a rich blood supply, and its harvesting causes low complications for patients. This review focuses on the characteristics and osteogenic capability of stem cells derived from BFP as a valuable cell source for bone tissue engineering. An electronic search was performed on all in vitro and in vivo studies that used stem cells from BFP for the purpose of bone tissue engineering from 2010 until 2016. This review was organized according to the PRISMA statement. Adipose-derived stem cells derived from BFP (BFPSCs) were compared with adipose tissues from other parts of the body (AdSCs). Moreover, the osteogenic capability of dedifferentiated fat cells (DFAT) derived from BFP (BFP-DFAT) has been reported in comparison with BFPSCs. BFP is an easily accessible source of stem cells that can be obtained via the oral cavity without injury to the external body surface. Comparing BFPSCs with AdSCs indicated similar cell yield, morphology, and multilineage differentiation. However, BFPSCs proliferate faster and are more prone to producing colonies than AdSCs.
\end{abstract}

\section{Introduction}

Mesenchymal stem cells (MSCs) derived from bone marrow aspirates have been frequently used as a cell source in bone tissue engineering [1]. However, several problems are associated with the clinical application of bone marrow stem cells (BMSCs) [1]. The harvesting procedure is associated with pain and discomfort for patients, and their differentiation capability is dependent on the donor age [2].
Adipose tissues have been introduced as a promising source of MSCs that can be obtained with minimal discomfort for patients, since subcutaneous adipose tissues are usually discarded after aesthetic surgical procedures. In addition, several studies have shown that the cell yield from adipose tissues is 100 to 500 times greater than that from bone marrow aspirates [3-5]. Therefore, minimally invasive procedures can be used to obtain a high number of MSCs with similar multilineage capabilities [6-8]. However, not all patients undergo liposuction, and fat distribution is dependent on body weight. 
Recently, Farre-Guasch et al. isolated adipose-derived stem cells (AdSCs) from a mass of fatty tissue in the oral cavity called Bichat's fat pad or the buccal fat pad (BFP). These cells have a similar phenotype to AdSCs from abdominal subcutaneous adipose tissue [9]. Under appropriate conditions, AdSCs derived from BFP (BFPSCs) have been shown to differentiate into chondrocytes, osteoblasts, or adipocytes in vitro [9]. Moreover, Shiraishi et al. reported that BFPSCs can form engineered bone in the back subcutaneous pockets of nude mice [10]. Khojasteh and Sadeghi recently used BFPSCs in conjunction with iliac bone block grafts and showed an increase in the amount of new bone formation and a decrease in secondary bone resorption in extensively atrophic jaws [11].

In addition to BFPSCs, dedifferentiated fat cells (DFAT) derived from BFP (BFP-DFAT) can be produced from mature adipocytes by a convenient method called ceiling culture technique. These cells possess high potential for regeneration of the bone and periodontal tissues [10, 12]. Therefore, BFP could be considered as a potential cell source for bone engineering in oral and craniofacial areas since it is easy to harvest and provides a proper quantity of tissue for cell isolation. The present study reviews research on the characteristics and osteogenic capability of stem cells derived from BFP as a promising cell source for bone tissue engineering in the oral and craniofacial regions.

\section{Materials and Methods}

This systematic review has been organized according to the preferred reporting items for systematic reviews and metaanalysis (PRISMA) statement.

2.1. Eligibility Criteria. This review included all in vitro and in vivo studies that used BFPSCs and BFP-DFAT cells from human or animal sources for bone regeneration. Abstracts, reviews, letters, and theses were excluded. Studies were excluded if they used the BFP flap or mass (i.e., without cells) and if they did not focus on bone formation or differentiation towards the osteoblast lineage.

\subsection{Search Strategy and Study Selection. The PubMed/MED-} LINE, EMBASE, Web of Science, and Cochrane electronic databases were searched for relevant studies published between January 2010 and November 2016. No limitation in language was applied in the search process. The following search terms were used, in which " $m$ " represents the $\mathrm{MeSH}$ terms and "tiab" represents the title or abstract: ("buccal fat pad" (mh) or "buccal fat pad" (tiab) or "BFP" (mh) or "BFP" (tiab)) and ("cell" (tiab) or "stem cell" (tiab) or "tissue engineering" (tiab) or "adipose tissue stem cell” (tiab)). Additionally, a manual search was also performed in the following journals in the given time periods: Stem Cells, Stem Cell Research, Journal of Stem Cells, and Regenerative Medicine.

Initial screening of titles and abstracts was carried out based on the inclusion and exclusion criteria, and full texts of all eligible studies were obtained. Two independent reviewers extracted and processed data for analysis according to the predefined eligibility criteria. In case of any disagreement, agreement was obtained following a discussion with the third reviewer. The fourth and fifth reviewers contributed to discussion section.

2.3. Data Items. The results and data were extracted from the full text of the articles. The studies were then classified and summarized as in vitro and in vivo studies. In in vitro studies, the following outcomes were assessed: alkaline phosphate (ALP) activity, alizarin red staining, osteocalcin (OCN) content, and gene expression using reverse transcription polymerase chain reaction (RT-PCR). The results of histological evaluation and radiographic evaluation were also assessed for in vivo studies. Since the focus of the present review is the BFP stem cells derived from both human and animal origins, the sources of cells were also identified (Tables 1 and 2).

\section{Results}

As illustrated in the PRISMA flow diagram in Figure 1, the initial search retrieved a total of 406 studies. Following the initial screening of titles and abstracts, 16 studies were selected for final screening of the full texts. A total of 10 articles met the inclusion criteria and were included in the analysis (Figure 1). Of these 10 studies, seven were conducted in vitro $[9,12-17]$, and the other three were conducted both in vitro and in vivo $[10,11,18]$.

All in vitro studies except for two compared BFPSCs with other cell sources, including AdSCs, BMSCs, unrestricted somatic stem cells (USSCs), and subcutaneous adipose stem cells (SC-AdSCs) $[9,12-14,17]$. All studies derived stem cells from human volunteers except for a study by Niada et al., where BFPSCs were derived from swine and compared to SC-AdSCs [13]. Three of the 10 studies focused on BFPDFAT cells [14-16]. One experiment focused on the size of DFAT cells and compared small cells $(<40 \mu \mathrm{m})$ with large cells $(40-100 \mu \mathrm{m})$ based on the characteristics for MSCs [16].

Three studies reported in vivo results in addition to in vitro assessment $[10,11,18]$. Two studies reported bone formation results after the application of BFPSCs in animal models $[10,11]$, and one study performed human bone regeneration. Shiraishi et al. used recombinant human bone morphogenetic protein 2 (rhBMP2) with cells [10], and Nagasaki et al. combined low-intensity pulsed ultrasound and nanohydroxyapatite scaffolds for transplanting BFPSCs into the calvarial defects of mice [18]. Khojasteh and Sadeghi loaded BFPSCs on an allograft and implanted that in combination with autogenous iliac bone in severely atrophic jaws [11].

Data extracted on the characteristics of BFPSCs and SC-AdSCs are compared in Table 3. Tissue volume, number of cells, collagen deposition, ALP activity, and glycosaminoglycan (GAG) content have been shown to be greater in SC-AdSCs, but cell proliferation, morphology, size, adipogenic differentiation, and expression of MSCs markers are similar. In addition, unlike SC-AdSCs, BFPSCs are capable of producing colony-forming units $[9,12,13]$. 


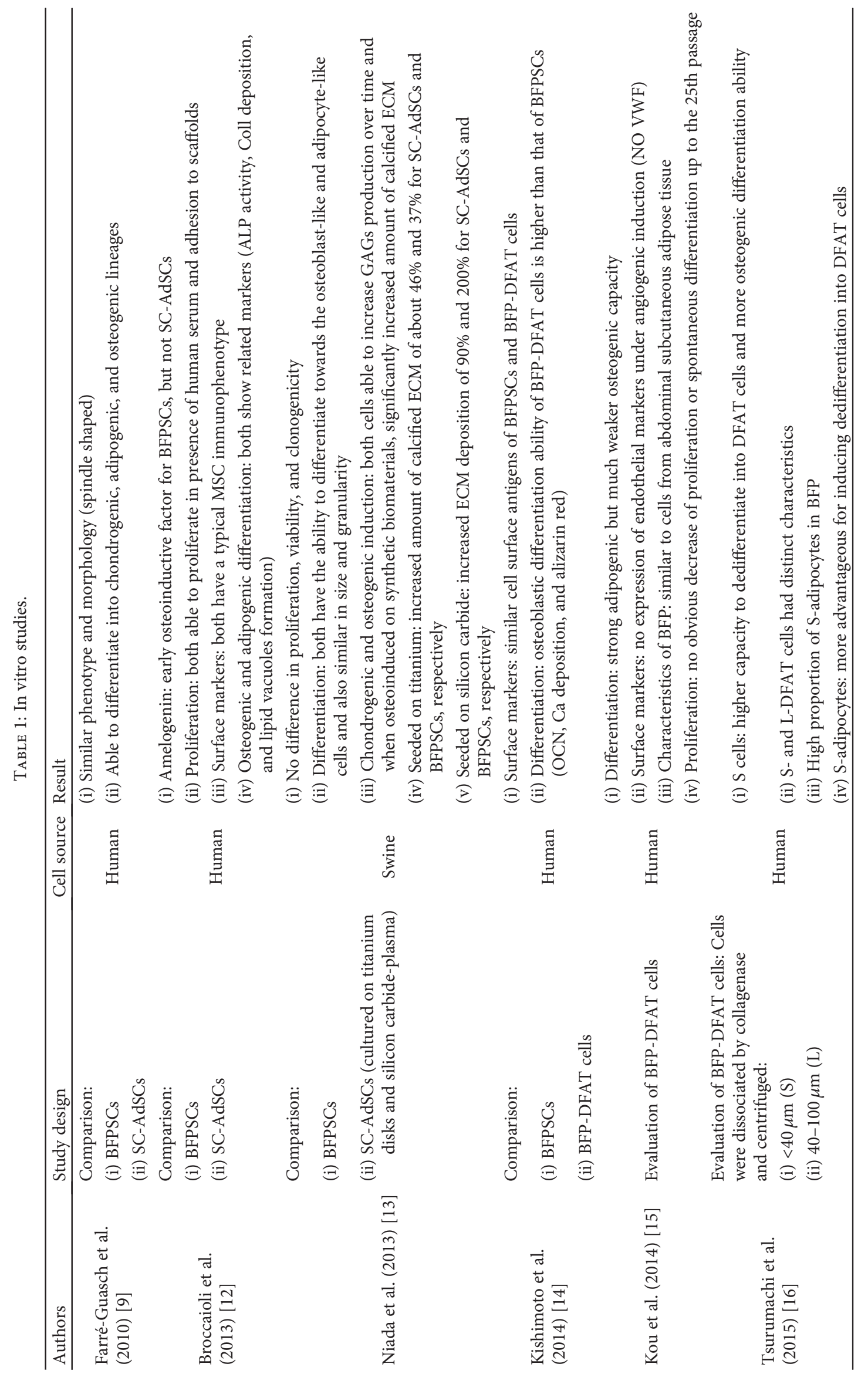




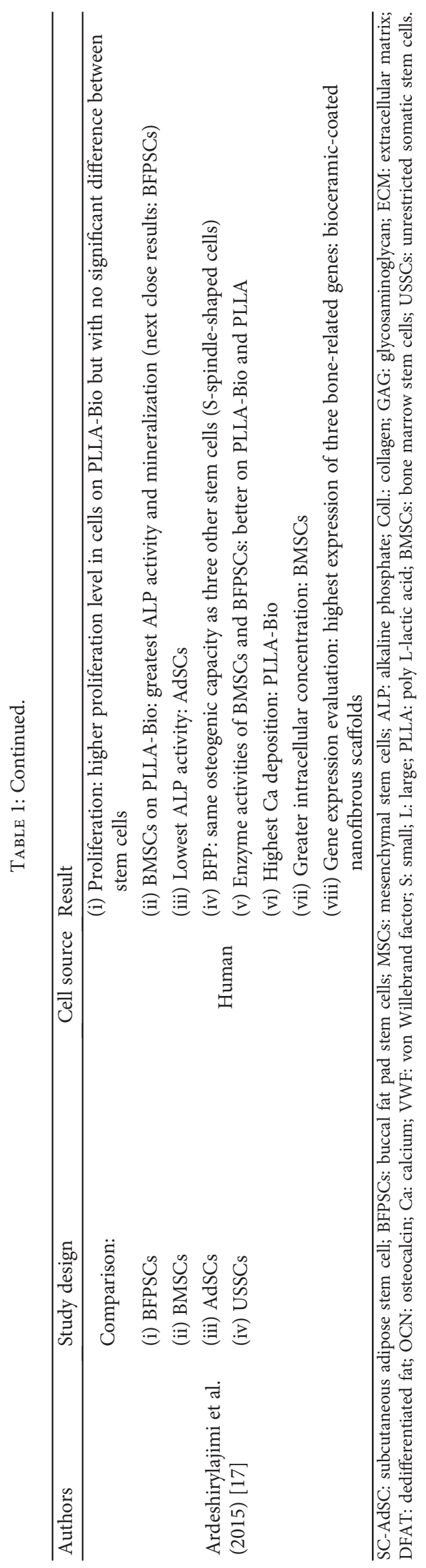


TABLE 2: In vivo studies.

Author Study design

Shiraishi et al. (2012) [10]

An efficient method of generating bone from BFPSCs using rhBMP-2

Human (2015) [18]

Combination of LIPUS \& NHA as scaffold for BFPSCs (transplantation in calvarial bone defects of nude mice)

Preliminary: BFPSCs with autogenous iliac

Khojasteh and Sadeghi (2015) [11] bone graft in treatment of maxillomandibular extreme jaw atrophy
Nagasaki et al.

Cell source Result

(i) BFPSCs can differentiate in vitro towards the osteoblastic lineage by addition of rhBMP-2 regardless of presence of osteoinductive reagents (ALP activity, calcification, and gene expression)

(ii) Adipogenic genes were detectable only in cultures with rhBMP-2 and OSR.

(iii) BFPSCs: formed engineered bone when pretreated with rhBMP-2 for inducing mature osteoblastic differentiation

(iv) BFPSCs: had characteristic spindle shape and formed a monolayer

(i) Significantly increased the osteogenic differentiation of BFPSCs in vitro and in vivo

Human (ii) Enhanced new bone formation of margin of defects

(iii) Synergistic effects of LIPUS and NHA: capable of effectively inducing differentiation of BFPSCs into osteoblasts

(i) Mean bone width change at the graft site: greater in the test group than in the control group $(3.94-1.62 \mathrm{~mm}$ versus $3.01-0.89 \mathrm{~mm}$ )

Human (ii) New bone formation: $65.32 \%$ in the test group versus $49.21 \%$ in the control group

(iii) Increased amount of new bone formation \& decreased secondary bone resorption in extensively atrophic jaws

BFPSCs: buccal fat pad stem cells; ALP: alkaline phosphate; NHA: nanohydroxyapatite; rhBMP2: recombinant human bone morphogenetic protein, LIPUS: low-intensity pulsed ultrasound; OSR: osteoinductive reagents.

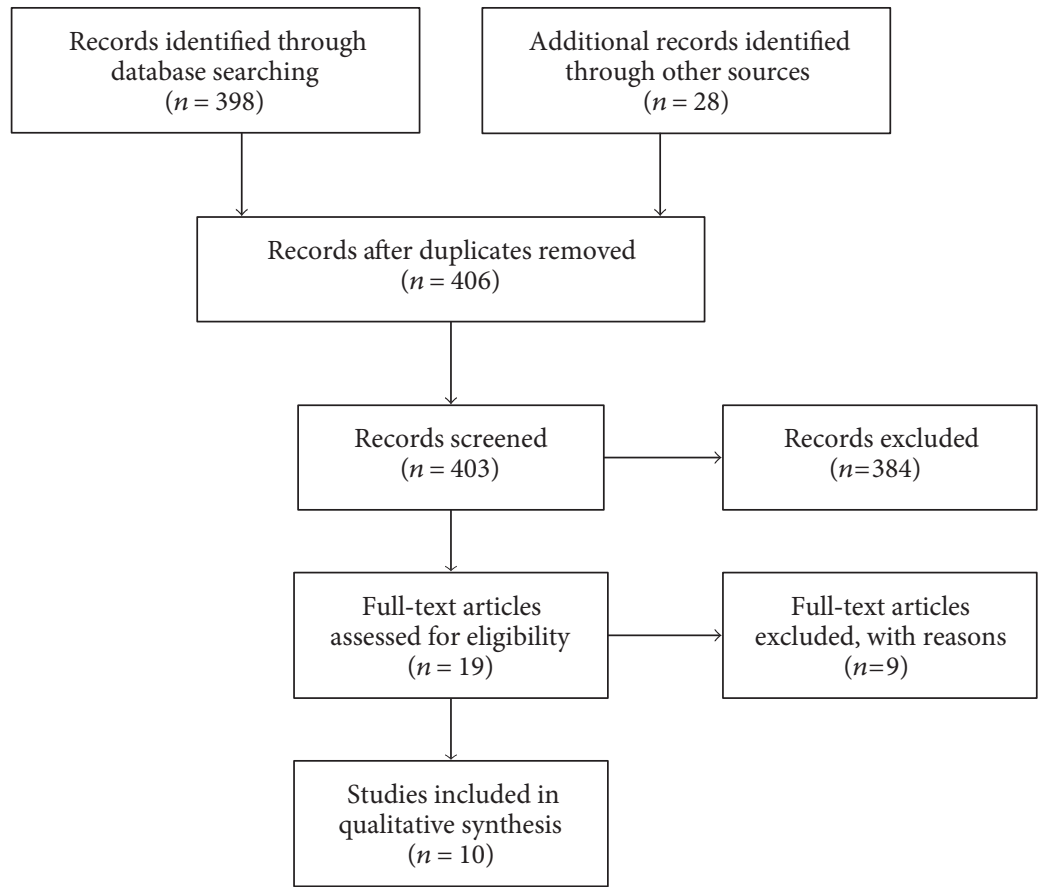

FIgURE 1: Search strategy flowchart. 
TABLE 3: Comparison between BFPSCs and SC-AdSCs.

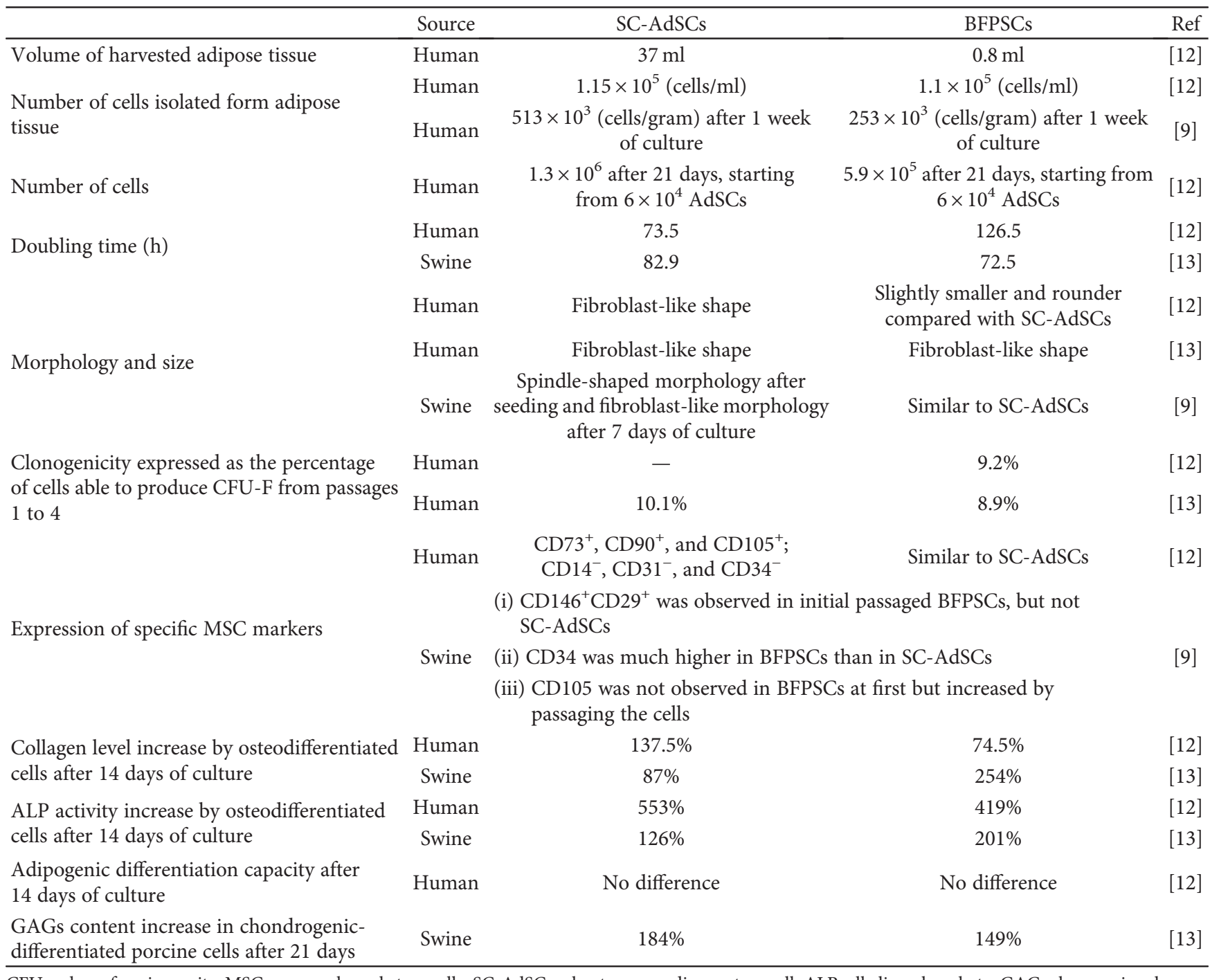

CFU: colony-forming units; MSCs: mesenchymal stem cells; SC-AdSC: subcutaneous adipose stem cell; ALP: alkaline phosphate; GAG: glycosaminoglycan.

\section{Discussion}

Adipose tissue contains two different fractions: (1) stromal vascular fraction (SVF), which includes MSCs (preadipocytes), fibroblasts, and erythrocytes and (2) mature adipocytes [9]. AdSCs isolated from the SVF were considered to be the key MSCs within this tissue and can be induced towards adipocytes, osteocytes, chondrocytes, myocytes, and neurons [19-21]. Since the SVF has a complex structure and cellular composition, AdSCs derived from SVF, particularly in early passages, are heterogeneous populations composed of cells with various characteristics and behaviors [9, 22-27].

Mature adipocytes are another abundant type of cells in fat tissue, and they have also shown dynamic plasticity to be converted into DFAT cells by a ceiling culture technique [28-30]. Unlike terminally differentiated adipocytes, DFAT cells have significant and steady proliferation capability [30-33]. In contrast to AdSCs, DFAT cells have been shown to have a more homogeneous cell population $[15,16,30]$. In addition, a greater number of DFAT cells can be produced from a given amount of fat tissue [34, 35].

The cellular nature and differentiation stage of DFAT cells have not been fully clarified. However, several studies have suggested that DFAT cells are in the late stage of the differentiation process and classified them into preadipocytes $[36,37]$. Similar to preadipocytes, DFAT cells could be redifferentiated into lipid-filled adipocytes under proper induction [29, 30, 38, 39]. Evaluations of stem cell-related markers and multilineage differentiation assays (i.e., adipogenesis, chondrogenesis, and osteogenesis) have also suggested that DFAT cells are similar to AdSCs $[30,38]$. Poloni et al. also produced neurospheres from DFAT cells [40, 41], indicating that their multipotency might extend beyond the mesodermal lineages $[40,42]$. Kishimoto et al. demonstrated that DFAT cells also showed proliferation and differentiation towards osteoblasts when they were cultured on self-assembling peptide or titanium fiber mesh scaffolds 


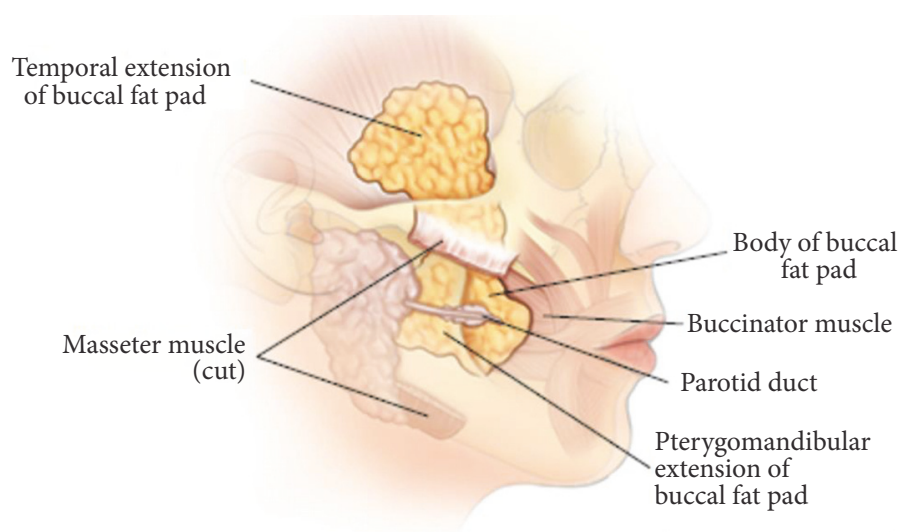

(a)

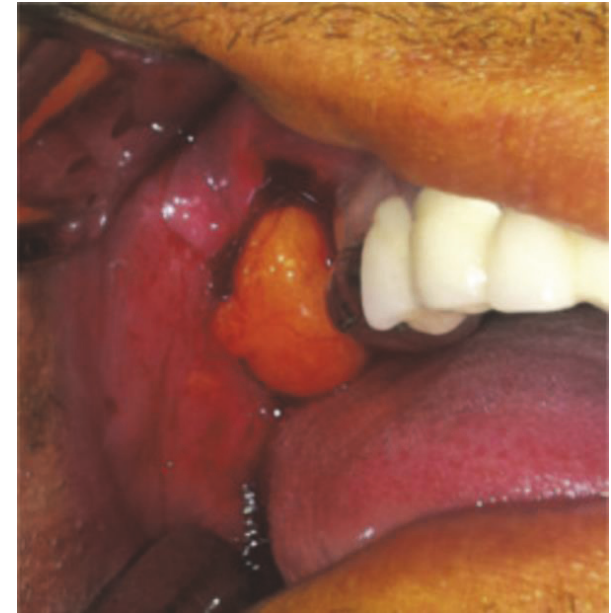

(b)

FIgURE 2: (a) Buccal fat pad anatomic location; permission granted from Muresan and Matarasso [92]. (b) Harvesting buccal fat pad with minimal discomfort for patients; permission granted from Khojasteh and Sadeghi [11].

$[14,43,44]$. These findings highlight the hypothesis that DFAT cells are multipotent cells and have potential for use in tissue engineering.

One major goal of tissue engineering is to find a source of stem cells that can provide an adequate number for clinical application with minimal morbidity, maximal proliferation rate, and high differentiation potential $[9,17]$. The BFP in the oral cavity is a mass of specialized fatty tissue that is distinct from subcutaneous fat and is located on either sides of the face between the buccinator muscle and other superficial muscles (Figure 2(a)) [45-48]. The BFP has a rich vascular supply [49-52] and can be harvested easily by an intraoral flap with minimal discomfort and complications for patients (Figure 2(b)) [9, 52-54]. In addition, BFP is a discarded tissue in plastic surgery for cheek reduction [13]. Furthermore, it is routinely administered in the treatment of the bone, periodontal defects [49, 55-59], congenital oroantral diseases, oronasal diseases [60], congenital cleft palate repair [61], oral submucous fibrosis [62, 63], intraoral malignant defects [64], and cheek mucosa defects [65].

Another advantage of BFP over subcutaneous fat is that its size appears to be similar among different people, independent of body weight and fat distribution [66]. Patients with little subcutaneous fat have BFP with normal weight and volume [9]. Recent studies have shown that both AdSCs $[9,10]$ and DFAT cells [14] isolated from human BFP (i.e., BFPSCs and BFP-DFAT cells) are similar to SC-AdSCs and possess high potential for regeneration of the bone and periodontal tissues [10, 12]. These properties may make the BFP a desirable cell source for tissue engineering and cell isolation.

4.1. Characteristics of BFPSCs. Since BFP is easily accessible via the oral cavity without injury to the external body surface, several research groups have recently evaluated the behavior of isolated AdSCs from the BFP as a proper source of adult cells for clinical applications [13].
4.1.1. Morphology of Isolated BFPSCs. BFPSCs have been reported to remain in a quiescent state during 2-4 days of culture and showed spindle-shaped morphology similar to AdSCs, BMSCs, and USSCs [17]. Afterward, they began to multiply rapidly, formed a monolayer of large flat cells, and exhibited a more fibroblast-like morphology characteristic of AdSCs [9].

4.1.2. BFPSC Surface Marker Profile. Cell surface markers on BFPSCs were characterized by immunofluorescence combined with flow cytometric analysis [10, 12, 67]. BFPSCs expressed MSC-defined markers, including CD73, CD90, and CD29, whereas they did not express lymphocyte or leucocyte antigens [12] and hematopoietic markers such as CD14, CD31, CD34 [9, 12], CD45 [10], CD19, and HLADR [9]. In addition, Traktuev et al. reported that BFPSCs showed some expression of CD34, which is characteristic of fresh AdSCs [68]. However, this marker declined with passage in AdSCs [9]. CD $34^{+}$cells have been shown to stimulate angiogenesis, and they are involved in neovascularization processes that facilitate healing of damaged tissues $[69,70]$.

Similar to other AdSCs, freshly isolated BFPSCs lack expression of CD105, but expression of this marker increases rapidly after seeding $[20,71]$. AdSCs also usually lack expression of CD146, a characteristic marker of endothelial cells as well as vascular smooth muscle cells. However, Farré-Guasch et al. found a small population of CD146 cells in the first passages of BFPSCs [9]. The presence of this CD146contaminated population, as well as the presence of CD34 cells, might be due to the highly enriched blood vessel supply in BFP [72]. This could be related to the excellent woundhealing properties of BFP as a pedicled graft in oral surgery for treatment of oroantral communications [55, 73], maxillary defects [51], oral submucous fibrosis [74], and vocal cord defects [75].

4.1.3. Multilineage Differentiation Potential of BFPSCs. Several researchers have shown that BFPSCs are multipotent 
and differentiate towards osteogenic, adipogenic, and chondrogenic lineages in the presence of inductive stimuli $[9,12,76,77]$. Broccaioli et al. showed that after 14 days of osteogenic induction, BFPSCs showed a significant upregulation of two specific markers, ALP activity and collagen deposition [12]. Farré-Guasch et al. also showed that after 1 week of culture in osteogenic medium, BFPSCs changed their morphology from spindle shaped to more polygon shaped, which was accompanied by an increase in ALP activity [9]. They reported that BFPSCs cultured in osteogenic medium showed osteocalcin expression. In addition, Niada et al. demonstrated the expression of core-binding factor alpha subunit 1 (CBFA1) and osteonectin. They also showed that compared with undifferentiated cells, osteogenic-differentiated BFPSCs derived from swine significantly increased the production of bone-specific markers, such as collagen, calcified extracellular matrix (ECM), ALP, and osteonectin [13].

After adipogenic induction of BFPSCs, the classic fibroblast-like shape of human AdSCs changed, and BFPSC populations showed intracellular lipid vacuoles that increased in size and number during culture $[9,12,13]$. Farré-Guasch et al. showed increased expression levels of a specific adipocyte marker during culture, peroxisomeproliferating receptor gamma $(\operatorname{PPAR} \gamma)$, reaching approximately four times higher induction compared to those of undifferentiated BFPSCs [9]. Some studies also showed that BFPSCs synthesized cartilage matrix molecules and produced an extracellular matrix characteristic for chondrocytes when grown in chondrogenic medium. Farré-Guasch et al. observed that after five days of chondrogenic induction, BFPSC morphology became more spheroid shaped [9]. Immunohistochemistry in differentiated BFPSCs indicated Toluidine blue-stained nodules indicative of a proteoglycan matrix characteristic for cartilage and expression of collagen II, a marker believed to be specific for articular cartilage. In addition, increased expression of the master chondrogenic factor, SOX9, was observed in BFPSCs, followed by decreased expression of the adipogenic marker $\operatorname{PPAR} \gamma$ when they induced towards the chondroblast lineage [9]. Niada et al. also observed GAG content in chondrogenic differentiated BFPSCs following three weeks of induction [13].

4.1.4. Effect of Osteoinductive Agents on Bone Formation of BFPSCs. It is well known that rhBMP-2 enhances osteogenic differentiation of BMSCs [78]. However, it has been suggested that rhBMP-2 may not influence the osteogenic differentiation of AdSCs [25, 79]. Shiraishi et al. analyzed the capability of rhBMP-2 to induce osteogenesis on BFPSCs cultured in different culture conditions (i.e., osteoinductive reagents (OS), rhBMP2 (BMP), and the combination of BMP and OS (BMP-OS)) [10]. Their results indicated that rhBMP-2 strongly induced the osteogenic differentiation of human BFPSCs. After 10-14 days in culture, rhBMP-2 treatments (BMP and BMP-OS) induced distinct and substantial calcified-nodule formation and the expression of osteogenic markers in BFPSCs. In addition, they showed that BFPSCs pretreated with BMP-OS generated abundant bone tissue upon in vivo transplantation to the back subcutaneous pockets of nude mice [10].

Amelogenin (AM) is the most abundant enamel matrix protein, and it is favored for the repair of periodontal defects. Broccaioli et al. indicated that osteogenic differentiation of BFPSCs is specifically induced and upregulated by AM with a synergic effect with other osteoinductive factors [12], which was also reported for bone marrow MSCs [80-82]. This effect is more evident for BFPSCs than for SC-AdSCs, possibly due to the natural localization of BFPSCs, which could make them more prone to responding to stimuli naturally secreted in the same area of the body [12].

4.2. Comparison between BFPSCs and SC-AdSCs. Several research groups compared AdSCs derived from different areas of the body and evaluated their behavior in vitro to identify a convenient source for future preclinical studies (Table 1).

4.2.1. Isolated Cell Yield. Several studies showed that the number of SC-AdSCs is similar to the number of BFPSCs, despite the different amounts of raw adipose tissues $[12,32]$. However, Farré-Guasch et al. observed that the number of BFPSCs was two times higher than the number of SC-AdSCs after one week of culture. They admitted that this difference might be due to the differences in age, intrinsic characteristics of the patients, or particular properties of the adipose source [9].

4.2.2. Size and Morphology. Several studies reported that both BFPSCs and SC-AdSCs showed similar morphology (fibroblast-like morphology) [9, 10, 13]. However, Broccaioli et al. observed that BFPSCs appeared slightly smaller and rounder than SC-AdSCs [12].

4.2.3. Expression of Specific MSC Markers. Both types of cells similarly expressed defined MSC markers. Farré-Guasch et al. reported that the expression of CD34 was much higher in BFPSCs than in SC-AdSCs [9]. They also found the expression of CD146 in a small population of CD146 cells in the first passages of BFPSCs, but not in SC-AdSCs.

4.2.4. Proliferation and Viability. Broccaioli et al. showed that SC-AdSCs proliferated faster than BFPSCs, with an average doubling time of $73 \mathrm{~h}$ compared to $126 \mathrm{~h}$. This was also confirmed through a viability test, in which MTT incorporation by SC-AdSCs was mildly higher than that by BFPSCs [12]. However, similar doubling times were observed for BFPSCs and SC-AdSCs derived from swine [13].

4.2.5. Colony Formation. Broccaioli et al. showed that BFPSCs were more prone to producing colonies than SCAdSCs [12]. Interestingly, BFPSCs showed a significant increase in colony formation in late passages (from passages 7 to 9), suggesting a delayed selection of progenitor cells [12]. However, no significant difference has been observed between colony formation of porcine SC-AdSCs and BFPSCs from passages 1 to 4 [13].

4.2.6. Differentiation. Several researchers showed that both cell types are multipotent and differentiate into different cell 
lineages in the presence of inductive stimuli $[13,76,77]$. Broccaioli et al. showed that after 14 days of osteogenic induction, both BFPSCs and SC-AdSCs showed a significant upregulation of two specific markers, ALP activity, and collagen deposition [12]. Niada et al. also showed that osteogenic-differentiated SC-AdSCs and BFPSCs derived from swine significantly increased the production of bonespecific markers compared with undifferentiated cells, such as collagen, calcified ECM, ALP, and osteonectin. The greatest difference was observed in the collagen level of 7-day-osteoinduced BFPSCs, which was 7 times higher than that of osteoinduced SC-AdSCs [13]. Similar capabilities in adipogenic and chondrogenic differentiation have been observed in both BFPSCs and SC-AdSCs $[9,13,76]$.

4.2.7. Effect of Human Serum on the Growth of BFPSCs and SC-AdSCs. Considering possible clinical applications, Broccaioli et al. studied the ability of BFPSCs and SCAdSCs to grow in a medium supplemented with human serum [12]. Both populations were cultured in the presence of autologous serum (HAS) or heterologous serum (HHS), and their growth was compared to that of cells maintained in standard conditions (FBS). No differences in morphology were observed. In all the growth conditions, the AdSC populations maintained the fibroblast-like shape, and HAS induced a prompt increase in both BFPSC and SC-ASC numbers compared to other serums within 7 days. They noticed that the presence of human serum enhanced the proliferation rate of both cells types. This effect has not been previously observed in AdSCs, but similar heterogeneity in the response to autologous serum has also been described for BMSCs $[26,83-85]$ and could be explained by the differences in serum from the donors. Growing AdSCs in the presence of autologous serum could be a convenient and safe procedure in future cellular therapy, which would eliminate concerns about contact with animal proteins [12].

4.2.8. BFPSC and SC-AdSC Culture and Osteogenic Differentiation on Biomaterials. Several research groups evaluated the behaviors of BFPSCs (e.g., adhesion, growth, and differentiation) on natural and synthetic biomaterials and compared them with other stem cells. Broccaioli et al. showed that both SC-AdSCs and BFPSCs can adhere to the autologous alveolar bone and periodontal ligament [12]. Moreover, they reported that these cells efficiently adhered to a collagen membrane. However, BFPSCs have not shown tight bonding to suture filaments of polyglycolic acid compared to AdSCs [12].

Niada et al. evaluated the ability of porcine AdSCs derived from SC and BFP to grow and differentiate on two synthetic scaffolds: titanium and plasma-treated silicon carbide [13]. They showed that both porcine AdSCs adhered and differentiated on these scaffolds. Ardeshirylajimi et al. assessed the osteogenic differentiation potential of MSCs on surface-modified poly(L-lactide) acid (PLLA) nanofibers. The MSCs were derived from four different sites: BFP, the bone marrow, subcutaneous adipose tissue, and unrestricted somatic stem cells [17]. No significant difference was observed in the proliferation rates. All four types of stem cells were demonstrated to differentiate efficiently into osteoblast-like cells on nanofibrous scaffolds in osteogenic medium. The highest ALP activity and calcium content were observed in BMSCs cultured on PLLA. Interestingly, BFPSCs resembled BMSCs in both ALP and calcium content. In addition, the highest expression of bone-related gene expression (i.e., Runx2, osteonectin, and osteocalcin) was observed in BFPSCs and BMSCs compared to that in other stem cell types [17].

4.3. Characteristics of BFP-DFAT Cells. AdSCs are used extensively for tissue engineering, and various studies have reported their utility [22-24]. However, AdSCs at passage 0 include contaminating endothelial cells, smooth muscle cells, and pericytes [86]. In contrast to AdSCs, mature adipocytes are the most abundant cell type in adipose tissue and have dynamic plasticity to be converted into DFAT cells [31] Compared with ASCs, a relatively homogeneous cell population of DFAT cells has been revealed by flow cytometric analysis [31]. DFAT cells could not only redifferentiate into lipid-filled adipocytes in the same way as preadipocytes but they can also transdifferentiate into other cell types under proper conditions in vitro, including osteoblasts [14, 30,38], chondrocytes [30], and myocytes [87-90]. In vivo studies also suggested that DFAT cells could regenerate fat pads, ectopic osteoid tissue, or muscle tissue [30, 36-38, 88, 90].

4.3.1. Cell Surface Antigens. BFP-DFAT cells have been shown to be positive for CD90, CD105 [14], CD13, CD29, and CD44 [15] but negative for CD11b (monocyte marker), CD34 (hematopoietic progenitor cell marker), CD45 (leukocyte common antigen) [14], CD31, CD309, CD106, and alpha-smooth muscle actin $[15,30]$.

4.3.2. The Osteogenic Differentiation. Kou et al. showed that after 3 weeks of osteogenic culture, the DFAT cells demonstrated limited mineralized matrix indicated by alizarin red S staining, while a relatively large portion of cells assumed a multilocular appearance and they were positive for adipose staining [15]. Previous reports confirmed the expression of osteogenic transcription factors in DFAT cells, including Runx2, osteopontin, osteorix, and osteocalcin $[22,29,30]$. However, Kou et al. showed that DFAT cells exhibited lower potential of differentiating towards osteoblasts than an adipocyte lineage [15]. This could be due to the fact that the multipotent capacity of DFAT cells is tissue specific [15].

4.3.3. Small and Large DFAT Cells. Tsurumachi et al. divided adipocytes into two groups based on their size: those with cell diameters less than $40 \mu \mathrm{m}$ (small adipocytes: S-adipocytes) and those with diameters of $40-100 \mu \mathrm{m}$ (large adipocytes: L-adipocytes). They investigated the influence of the adipocyte size on the dedifferentiation efficiency into DFAT cells and compared the S- and L-DFAT cells based on the characteristics for MSCs. They showed that the S-adipocytes contained more juvenile adipocytes than the L-adipocytes. The results suggested higher rates of dedifferentiation for S-DFAT cells compared to those for L-DFAT cells and that the adipocyte size is 
positively associated with dedifferentiation. However, more studies are needed to reveal how the cell size could influence the efficiency of mature adipocyte dedifferentiation [16].

Tsurumachi et al. conducted flow cytometry and revealed higher CD146 expression in S-DFAT cells compared to that in L-DFAT cells, although both cells showed high expression levels of CD13, CD44, CD73, CD90, and CD105 [16]. $\mathrm{S}$-DFAT cells showed higher osteogenic potential in particular compared to the L-DFAT cells. Similarly, a comparison between AdSCs and DFAT cells obtained from BFP demonstrated more effective induction of osteoblasts from DFAT cells than from AdSCs [14]. S-DFAT cells also exhibited higher osteogenic potential than L-DFAT cells. The results suggested that S-DFAT cells have an advantage over L-DFAT cells and AdSCs in bone tissue engineering.

4.4. Comparison between BFPSCs and BFP-DFAT Cells. Matsumoto et al. reported that human AdSCs at passage 1 are $13.3 \%$ positive for CD11b (monocyte marker) and $12.8 \%$ positive for CD45 (leukocyte common antigen). However, human DFAT cells at passage 1 are negative for these markers, indicating greater homogenicity of DFAT cells compared with AdSCs [30]. Kishimoto et al. showed that the expression of osteoblastic differentiation markers (BAP, OCN, and calcium) in BFP-DFAT cells was more prevalent than that in BFPSCs [14]. However, they indicated that the difference in the osteoblastic differentiation ability of BFPSCs and BFP-DFAT cells was not because of the difference of purity in the cell populations [14]. The same group also reported various osteoblastic differentiation abilities between human DFAT cells derived from the submandibular and human BMSCs [91]. Gene expression of Runx2, ALP, OCN expression, and calcium deposition was higher in DFAT cells than in bone marrow MSCs. More studies are needed to come to a general conclusion regarding the osteogenic capability of BFP-DFAT.

\section{Conclusions}

This study has reviewed the characteristics and osteogenic capability of AdSCs derived from BFP. This source of cells was also compared with other AdSCs from other parts of the body. BFP is an easily accessible source of stem cells that can be obtained easily via the oral cavity without injury to the external body surface. Its size is similar between people and independent of body weight and fat distribution. Comparing BFPSCs with other AdSCs showed similarities in cell yield, morphology, and multilineage differentiation. However, BFP has been shown to proliferate faster and is more prone to producing colonies. Limited studies have been conducted on the osteogenic capability of BFP-DFAT cells, which makes conclusions infeasible.

\section{Conflicts of Interest}

The authors declare that there is no conflict of interest regarding the publication of this paper.

\section{Acknowledgments}

This research was supported by the Research Deputy, Dental School, Shahid Behehsti University of Medical Sciences.

\section{References}

[1] A. Khojasteh, H. Behnia, S. G. Dashti, and M. Stevens, "Current trends in mesenchymal stem cell application in bone augmentation: a review of the literature," Journal of Oral and Maxillofacial Surgery, vol. 70, no. 4, pp. 972-982, 2012.

[2] M. Nishimori, Y. Yamada, K. Hoshi et al., "Health-related quality of life of unrelated bone marrow donors in Japan," Blood, vol. 99, no. 6, pp. 1995-2001, 2002.

[3] J. K. Fraser, I. Wulur, Z. Alfonso, and M. H. Hedrick, "Fat tissue: an underappreciated source of stem cells for biotechnology," Trends in Biotechnology, vol. 24, no. 4, pp. 150154, 2006.

[4] B. M. Strem, K. C. Hicok, M. Zhu et al., "Multipotential differentiation of adipose tissue-derived stem cells," The Keio Journal of Medicine, vol. 54, no. 3, pp. 132-141, 2005.

[5] P. C. Baer and H. Geiger, "Adipose-derived mesenchymal stromal/stem cells: tissue localization, characterization, and heterogeneity," Stem Cells International, vol. 2012, Article ID 812693, 11 pages, 2012.

[6] N. Quirici, C. Scavullo, L. de Girolamo et al., "Anti-L-NGFR and CD34 monoclonal antibodies identify multipotent mesenchymal stem cells in human adipose tissue," Stem Cells and Development, vol. 19, no. 6, pp. 915-925, 2010.

[7] L. de Girolamo, M. F. Sartori, E. Arrigoni et al., "Human adipose-derived stem cells as future tools in tissue regeneration: osteogenic differentiation and cell-scaffold interaction," The International Journal of Artificial Organs, vol. 31, no. 6, pp. 467-479, 2008.

[8] L. de Girolamo, S. Lopa, E. Arrigoni, M. F. Sartori, F. W. Baruffaldi Preis, and A. T. Brini, "Human adipose-derived stem cells isolated from young and elderly women: their differentiation potential and scaffold interaction during in vitro osteoblastic differentiation," Cytotherapy, vol. 11, no. 6, pp. 793-803, 2009.

[9] E. Farré-Guasch, C. Marti-Page, F. Hernadez-Alfaro, J. Klein-Nulend, and N. Casals, "Buccal fat pad, an oral access source of human adipose stem cells with potential for osteochondral tissue engineering: an in vitro study," Tissue Engineering. Part C, Methods, vol. 16, no. 5, pp. 1083-1094, 2010.

[10] T. Shiraishi, Y. Sumita, Y. Wakamastu, K. Nagai, and I. Asahina, "Formation of engineered bone with adipose stromal cells from buccal fat pad," Journal of Dental Research, vol. 91, no. 6, pp. 592-597, 2012.

[11] A. Khojasteh and N. Sadeghi, "Application of buccal fat padderived stem cells in combination with autogenous iliac bone graft in the treatment of maxillomandibular atrophy: a preliminary human study," International Journal of Oral and Maxillofacial Surgery, vol. 47, no. 5, pp. 864-871, 2016.

[12] E. Broccaioli, S. Niada, G. Rasperini et al., "Mesenchymal stem cells from Bichat's fat pad: in vitro comparison with adiposederived stem cells from subcutaneous tissue," Biores Open Access, vol. 2, no. 2, pp. 107-117, 2013.

[13] S. Niada, L. M. Ferreira, E. Arrigoni et al., "Porcine adiposederived stem cells from buccal fat pad and subcutaneous adipose tissue for future preclinical studies in oral surgery," Stem Cell Research \& Therapy, vol. 4, no. 6, p. 148, 2013. 
[14] N. Kishimoto, Y. Momota, Y. Hashimoto et al., "The osteoblastic differentiation ability of human dedifferentiated fat cells is higher than that of adipose stem cells from the buccal fat pad," Clinical Oral Investigations, vol. 18, no. 8, pp. 1893-1901, 2014.

[15] L. Kou, X. W. Lu, M. K. Wu et al., "The phenotype and tissuespecific nature of multipotent cells derived from human mature adipocytes," Biochemical and Biophysical Research Communications, vol. 444, no. 4, pp. 543-548, 2014.

[16] N. Tsurumachi, D. Akita, K. Kano et al., "Small buccal fat pad cells have high osteogenic differentiation potential," Tissue Engineering Part C: Methods, vol. 22, no. 3, pp. 250-259, 2016.

[17] A. Ardeshirylajimi, M. Mossahebi-Mohammadi, S. Vakilian et al., "Comparison of osteogenic differentiation potential of human adult stem cells loaded on bioceramic-coated electrospun poly (L-lactide) nanofibres," Cell Proliferation, vol. 48, no. 1, pp. 47-58, 2015.

[18] R. Nagasaki, Y. Mukudai, Y. Yoshizawa et al., "A combination of low-intensity pulsed ultrasound and nanohydroxyapatite concordantly enhances osteogenesis of adipose-derived stem cells from buccal fat pad," Cell Medicine, vol. 7, no. 3, pp. 123-131, 2015.

[19] T. T. Tran and C. R. Kahn, "Transplantation of adipose tissue and stem cells: role in metabolism and disease," Nature Reviews. Endocrinology, vol. 6, no. 4, pp. 195-213, 2010.

[20] A. Schaffler and C. Buchler, "Concise review: adipose tissue-derived stromal cells-basic and clinical implications for novel cell-based therapies," Stem Cells, vol. 25, no. 4, pp. 818-827, 2007.

[21] J. M. Gimble, A. J. Katz, and B. A. Bunnell, “Adipose-derived stem cells for regenerative medicine," Circulation Research, vol. 100, no. 9, pp. 1249-1260, 2007.

[22] A. J. Katz, A. Tholpady, S. S. Tholpady, H. Shang, and R. C. Ogle, "Cell surface and transcriptional characterization of human adipose-derived adherent stromal (hADAS) cells," Stem Cells, vol. 23, no. 3, pp. 412-423, 2005.

[23] S. Gronthos, D. M. Franklin, H. A. Leddy, P. G. Robey, R. W. Storms, and J. M. Gimble, "Surface protein characterization of human adipose tissue-derived stromal cells," Journal of Cellular Physiology, vol. 189, no. 1, pp. 54-63, 2001.

[24] T. Rada, R. L. Reis, and M. E. Gomes, “Adipose tissue-derived stem cells and their application in bone and cartilage tissue engineering," Tissue Engineering Part B, vol. 15, no. 2, pp. 113-125, 2009.

[25] P. A. Zuk, M. Zhu, H. Mizuno et al., "Multilineage cells from human adipose tissue: implications for cell-based therapies," Tissue Engineering, vol. 7, no. 2, pp. 211-228, 2001.

[26] H. Mizuno, M. Tobita, and A. C. Uysal, "Concise review: adipose-derived stem cells as a novel tool for future regenerative medicine," Stem Cells, vol. 30, no. 5, pp. 804810,2012

[27] R. Ogawa, H. Mizuno, A. Watanabe, M. Migita, T. Shimada, and H. Hyakusoku, "Osteogenic and chondrogenic differentiation by adipose-derived stem cells harvested from GFP transgenic mice," Biochemical and Biophysical Research Communications, vol. 313, no. 4, pp. 871-877, 2004.

[28] H. Sugihara, N. Yonemitsu, S. Miyabara, and K. Yun, "Primary cultures of unilocular fat cells: characteristics of growth in vitro and changes in differentiation properties," Differentiation, vol. 31, no. 1, pp. 42-49, 1986.
[29] S. S. Tholpady, C. Aojanepong, R. Llull et al., "The cellular plasticity of human adipocytes," Annals of Plastic Surgery, vol. 54, no. 6, pp. 651-656, 2005.

[30] T. Matsumoto, K. Kano, D. Kondo et al., "Mature adipocytederived dedifferentiated fat cells exhibit multilineage potential," Journal of Cellular Physiology, vol. 215, no. 1, pp. 210-222, 2008.

[31] A. Conde-Green, L. S. Baptista, N. F. de Amorin et al., "Effects of centrifugation on cell composition and viability of aspirated adipose tissue processed for transplantation," Aesthetic Surgery Journal, vol. 30, no. 2, pp. 249-255, 2010.

[32] J. B. Mitchell, K. McIntosh, S. Zvonic et al., "Immunophenotype of human adipose-derived cells: temporal changes in stromal-associated and stem cell-associated markers," Stem Cells, vol. 24, no. 2, pp. 376-385, 2006.

[33] J. F. Shen, A. Sugawara, J. Yamashita, H. Ogura, and S. Sato, "Dedifferentiated fat cells: an alternative source of adult multipotent cells from the adipose tissues," International Journal of Oral Science, vol. 3, no. 3, pp. 117-124, 2011.

[34] S. Kono, T. Kazama, K. Kano, K. Harada, M. Uechi, and T. Matsumoto, "Phenotypic and functional properties of feline dedifferentiated fat cells and adipose-derived stem cells," Veterinary Journal, vol. 199, no. 1, pp. 88-96, 2014.

[35] S. J. Hong, E. Park, W. Xu, S. Jia, R. D. Galiano, and T. A. Mustoe, "Response of human mature adipocytes to hypoxiareoxygenation," Cytotherapy, vol. 16, no. 12, pp. 1656-1665, 2014.

[36] K. Yagi, D. Kondo, Y. Okazaki, and K. Kano, “A novel preadipocyte cell line established from mouse adult mature adipocytes," Biochemical and Biophysical Research Communications, vol. 321, no. 4, pp. 967-974, 2004.

[37] H. Nobusue, T. Endo, and K. Kano, "Establishment of a preadipocyte cell line derived from mature adipocytes of GFP transgenic mice and formation of adipose tissue," Cell and Tissue Research, vol. 332, no. 3, pp. 435-446, 2008.

[38] Y. Oki, S. Watanabe, T. Endo, and K. Kano, "Mature adipocytederived dedifferentiated fat cells can trans-differentiate into osteoblasts in vitro and in vivo only by all-trans retinoic acid," Cell Structure and Function, vol. 33, 2008.

[39] N. Ijichi, K. Ikeda, K. Horie-Inoue, K. Yagi, Y. Okazaki, and S. Inoue, "Estrogen-related receptor alpha modulates the expression of adipogenesis-related genes during adipocyte differentiation," Biochemical and Biophysical Research Communications, vol. 358, no. 3, pp. 813-818, 2007.

[40] A. Poloni, G. Maurizi, P. Leoni et al., "Human dedifferentiated adipocytes show similar properties to bone marrow-derived mesenchymal stem cells," Stem Cells, vol. 30, no. 5, pp. 965974, 2012.

[41] A. Poloni, G. Maurizi, S. Anastasi et al., "Plasticity of human dedifferentiated adipocytes toward endothelial cells," Experimental Hematology, vol. 43, no. 2, pp. 137-146, 2015.

[42] Y. Ohta, M. Takenaga, Y. Tokura et al., "Mature adipocytederived cells, dedifferentiated fat cells (DFAT), promoted functional recovery from spinal cord injury-induced motor dysfunction in rats," Cell Transplantation, vol. 17, no. 8, pp. 877-886, 2008.

[43] N. Kishimoto, Y. Momota, Y. Hashimoto, T. Omasa, and J. Kotani, "Self-assembling peptide RADA16 as a scaffold in bone tissue engineering using dedifferentiated fat cells," Journal of Oral Tissue Engineering, vol. 8, no. 3, pp. 151-161, 2011. 
[44] N. Kishimoto, Y. Momota, Y. Hashimoto, K. Ando, T. Omasa, and J. Kotani, "Dedifferentiated fat cells differentiate into osteoblasts in titanium fiber mesh," Cytotechnology, vol. 65, no. 1, pp. 15-22, 2013.

[45] H. M. Zhang, Y. P. Yan, K. M. Qi, J. Q. Wang, and Z. F. Liu, "Anatomical structure of the buccal fat pad and its clinical adaptations," Plastic and Reconstructive Surgery, vol. 109, no. 7, pp. 2509-2518, 2002.

[46] H. G. Gassner, A. Rafii, A. Young, C. Murakami, K. S. Moe, and W. F. Larrabee Jr, "Surgical anatomy of the face: implications for modern face-lift techniques," Archives of Facial Plastic Surgery, vol. 10, no. 1, pp. 9-19, 2008.

[47] M. Abad-Gallegos, R. Figueiredo, A. Rodriguez-Baeza, and C. Gay-Escoda, "Use of Bichat's buccal fat pad for the sealing of orosinusal communications. A presentation of 8 cases," Medicina Oral, Patología Oral y Cirugía Bucal, vol. 16, no. 2, pp. e215-e219, 2011.

[48] J. Sierra-Johnson and B. D. Johnson, "Facial fat and its relationship to abdominal fat: a marker for insulin resistance?" Medical Hypotheses, vol. 63, no. 5, pp. 783-786, 2004.

[49] S. A. El Haddad, M. Y. Abd El Razzak, and M. El Shall, "Use of pedicled buccal fat pad in root coverage of severe gingival recession defect," Journal of Periodontology, vol. 79, no. 7, pp. 1271-1279, 2008.

[50] E. Meyer, S. J. Liebenberg, and J. J. Fagan, "Buccal fat pad - a simple, underutilised flap," South African Journal of Surgery, vol. 50, no. 2, pp. 47-49, 2012.

[51] M. A. Amin, B. M. Bailey, B. Swinson, and H. Witherow, "Use of the buccal fat pad in the reconstruction and prosthetic rehabilitation of on oncological maxillary defects," The British Journal of Oral \& Maxillofacial Surgery, vol. 43, no. 2, pp. 148154, 2005.

[52] A. Baumann and R. Ewers, "Application of the buccal fat pad in oral reconstruction," Journal of Oral and Maxillofacial Surgery, vol. 58, no. 4, pp. 389-392, 2000.

[53] A. Tapia, R. Ruiz-de-Erenchun, and M. Rengifo, "Combined approach for facial contour restoration: treatment of malar and cheek areas during rhytidectomy," Plastic and Reconstructive Surgery, vol. 118, no. 2, pp. 491-497, 2006.

[54] R. J. Rohrich and J. E. Pessa, "The anatomy and clinical implications of perioral submuscular fat," Plastic and Reconstructive Surgery, vol. 124, no. 1, pp. 266-271, 2009.

[55] A. Abuabara, A. L. Cortez, L. A. Passeri, M. de Moraes, and R. W. Moreira, "Evaluation of different treatments for oroantral/oronasal communications: experience of 112 cases," International Journal of Oral and Maxillofacial Surgery, vol. 35, no. 2, pp. 155-158, 2006.

[56] A. Alkan, D. Dolanmaz, E. Uzun, and E. Erdem, "The reconstruction of oral defects with buccal fat pad," Swiss Medical Weekly, vol. 133, no. 33/34, pp. 465-470, 2003.

[57] R. Martin-Granizo, L. Naval, A. Costas et al., "Use of buccal fat pad to repair intraoral defects: review of 30 cases," The British Journal of Oral \& Maxillofacial Surgery, vol. 35, no. 2, pp. 81-84, 1997.

[58] A. Khojasteh, H. Mohajerani, F. Momen-Heravi, M. Kazemi, and M. Alikhasi, "Sandwich bone graft covered with buccal fat pad in severely atrophied edentulous maxilla: a clinical report," The Journal of Oral Implantology, vol. 37, no. 3, pp. 361-366, 2011.

[59] A. Hassani, A. Khojasteh, M. Alikhasi, and H. Vaziri, "Measurement of volume changes of sinus floor augmentation covered with buccal fat pad: a case series study," Oral Surgery, Oral Medicine, Oral Pathology, Oral Radiology, and Endodontology, vol. 107, no. 3, pp. 369-374, 2009.

[60] P. Egyedi, "Utilization of the buccal fat pad for closure of oro-antral and/or oro-nasal communications," Journal of Maxillofacial Surgery, vol. 5, pp. 241-244, 1977.

[61] B. Levi, S. J. Kasten, and S. R. Buchman, "Utilization of the buccal fat pad flap for congenital cleft palate repair," Plastic and Reconstructive Surgery, vol. 123, no. 3, pp. 10181021, 2009.

[62] K. L. Surej, N. M. Kurien, and N. Sakkir, "Buccal fat pad reconstruction for oral submucous fibrosis," National Journal of Maxillofacial Surgery, vol. 1, no. 2, pp. 164-167, 2010.

[63] K. Saravanan and V. Narayanan, "The use of buccal fat pad in the treatment of oral submucous fibrosis: a newer method," International Journal of Dentistry, vol. 2012, Article ID 935135, 6 pages, 2012.

[64] J. Chakrabarti, R. Tekriwal, A. Ganguli, S. Ghosh, and P. K. Mishra, "Pedicled buccal fat pad flap for intraoral malignant defects: a series of 29 cases," Indian Journal of Plastic Surgery, vol. 42, no. 1, pp. 36-42, 2009.

[65] S. Ferrari, A. Ferri, B. Bianchi, C. Copelli, A. S. Magri, and E. Sesenna, "A novel technique for cheek mucosa defect reconstruction using a pedicled buccal fat pad and buccinator myomucosal island flap," Oral Oncology, vol. 45, no. 1, pp. 59-62, 2009.

[66] J. M. Stuzin, L. Wagstrom, H. K. Kawamoto, T. J. Baker, and S. A. Wolfe, "The anatomy and clinical applications of the buccal fat pad," Plastic and Reconstructive Surgery, vol. 85, no. 1, pp. 29-37, 1990.

[67] M. Dominici, K. Le Blanc, I. Mueller et al., "Minimal criteria for defining multipotent mesenchymal stromal cells. The International Society for Cellular Therapy position statement," Cytotherapy, vol. 8, no. 4, pp. 315-317, 2006.

[68] D. O. Traktuev, S. Merfeld-Clauss, J. Li et al., "A population of multipotent CD34-positive adipose stromal cells share pericyte and mesenchymal surface markers, reside in a periendothelial location, and stabilize endothelial networks," Circulation Research, vol. 102, no. 1, pp. 77-85, 2008.

[69] V. Planat-Benard, J. S. Silvestre, B. Cousin et al., "Plasticity of human adipose lineage cells toward endothelial cells: physiological and therapeutic perspectives," Circulation, vol. 109, no. 5, pp. 656-663, 2004.

[70] R. Madonna and R. De Caterina, "In vitro neovasculogenic potential of resident adipose tissue precursors," American Journal of Physiology. Cell Physiology, vol. 295, no. 5, pp. C1271-C1280, 2008.

[71] H. Yoshimura, T. Muneta, A. Nimura, A. Yokoyama, H. Koga, and I. Sekiya, "Comparison of rat mesenchymal stem cells derived from bone marrow, synovium, periosteum, adipose and muscle," Cell and Tissue Research, vol. 327, no. 3, pp. 449-462, 2007.

[72] M. Crisan, S. Yap, L. Casteilla et al., "A perivascular origin for mesenchymal stem cells in multiple human organs," Cell Stem Cell, vol. 3, no. 3, pp. 301-313, 2008.

[73] E. J. de Moraes, "Closure of oroantral communication with buccal fat pad flap in zygomatic implant surgery: a case report," The International Journal of Oral \& Maxillofacial Implants, vol. 23, no. 1, p. 143, 2008.

[74] D. Mehrotra, R. Pradhan, and S. Gupta, "Retrospective comparison of surgical treatment modalities in 100 patients 
with oral submucous fibrosis," Oral Surgery, Oral Medicine, Oral Pathology, Oral Radiology, and Endodontics, vol. 107, no. 3, pp. e1-e10, 2009.

[75] E. Tamura, H. Fukuda, Y. Tabata, and M. Nishimura, "Use of the buccal fat [corrected] pad for vocal cord augmentation," Acta Oto-Laryngologica, vol. 128, p. 219, 2008.

[76] C. Q. Qu, G. H. Zhang, L. J. Zhang, and G. S. Yang, "Osteogenic and adipogenic potential of porcine adipose mesenchymal stem cells," In Vitro Cellular \& Developmental Biology. Animal, vol. 43, no. 2, pp. 95-100, 2007.

[77] L. Tang, Y. Yin, H. Zhou et al., "Proliferative capacity and pluripotent characteristics of porcine adult stem cells derived from adipose tissue and bone marrow," Cellular Reprogramming, vol. 14, no. 4, pp. 342-352, 2012.

[78] F. Lecanda, L. V. Avioli, and S. L. Cheng, "Regulation of bone matrix protein expression and induction of differentiation of human osteoblasts and human bone marrow stromal cells by bone morphogenetic protein-2," Journal of Cellular Biochemistry, vol. 67, no. 3, pp. 386-396, 1997.

[79] Y. F. Chou, P. A. Zuk, T. L. Chang, P. Benhaim, and B. M. Wu, "Adipose-derived stem cells and BMP2: Part 1. BMP2-treated adipose-derived stem cells do not improve repair of segmental femoral defects," Connective Tissue Research, vol. 52, no. 2, pp. 109-118, 2011.

[80] K. Tanimoto, Y. C. Huang, Y. Tanne et al., “Amelogenin enhances the osteogenic differentiation of mesenchymal stem cells derived from bone marrow," Cells, Tissues, Organs, vol. 196, no. 5, pp. 411-419, 2012.

[81] M. Izumikawa, K. Hayashi, M. A. Polan, J. Tang, and T. Saito, "Effects of amelogenin on proliferation, differentiation, and mineralization of rat bone marrow mesenchymal stem cells in vitro," The Scientific World Journal, vol. 2012, Article ID 879731, 8 pages, 2012.

[82] H. Jingchao, S. Rong, S. Zhongchen, and C. Lan, "Human amelogenin up-regulates osteogenic gene expression in human bone marrow stroma cells," Biochemical and Biophysical Research Communications, vol. 408, no. 3, pp. 437-441, 2011.

[83] S. A. Kuznetsov, M. H. Mankani, and P. G. Robey, "Effect of serum on human bone marrow stromal cells: ex vivo expansion and in vivo bone formation," Transplantation, vol. 70, no. 12, pp. 1780-1787, 2000.

[84] N. Yamamoto, M. Isobe, A. Negishi et al., "Effects of autologous serum on osteoblastic differentiation in human bone marrow cells," Journal of Medical and Dental Sciences, vol. 50, no. 1, pp. 63-69, 2003.

[85] A. Shahdadfar, K. Fronsdal, T. Haug, F. P. Reinholt, and J. E. Brinchmann, "In vitro expansion of human mesenchymal stem cells: choice of serum is a determinant of cell proliferation, differentiation, gene expression, and transcriptome stability," Stem Cells, vol. 23, no. 9, pp. 1357-1366, 2005.

[86] J. A. de Villiers, N. Houreld, and H. Abrahamse, "Adipose derived stem cells and smooth muscle cells: implications for regenerative medicine," Stem Cell Reviews, vol. 5, no. 3, pp. 256-265, 2009.

[87] T. Kazama, M. Fujie, T. Endo, and K. Kano, "Mature adipocyte-derived dedifferentiated fat cells can transdifferentiate into skeletal myocytes in vitro," Biochemical and Biophysical Research Communications, vol. 377, no. 3, pp. 780-785, 2008.

[88] T. Sakuma, T. Matsumoto, K. Kano et al., "Mature, adipocyte derived, dedifferentiated fat cells can differentiate into smooth muscle-like cells and contribute to bladder tissue regeneration," The Journal of Urology, vol. 182, no. 1, pp. 355-365, 2009.

[89] D. Obinata, T. Matsumoto, Y. Ikado et al., “Transplantation of mature adipocyte-derived dedifferentiated fat (DFAT) cells improves urethral sphincter contractility in a rat model," International Journal of Urology, vol. 18, no. 12, pp. 827-834, 2011.

[90] Q. Gao, L. Zhao, Z. Song, and G. Yang, "Expression pattern of embryonic stem cell markers in DFAT cells and ADSCs," Molecular Biology Reports, vol. 39, no. 5, pp. 5791-5804, 2012.

[91] F. Sakamoto, Y. Hashimoto, N. Kishimoto, Y. Honda, and N. Matsumoto, "The utility of human dedifferentiated fat cells in bone tissue engineering in vitro," Cytotechnology, vol. 65, no. 1, pp. 75-84, 2013.

[92] H. Muresan and A. Matarasso, Evaluation and treatment of the buccal fat pad. Plastic Surgery Pulse News, 7(1), Quality Medical Publishing, St. Louis, 2015. 

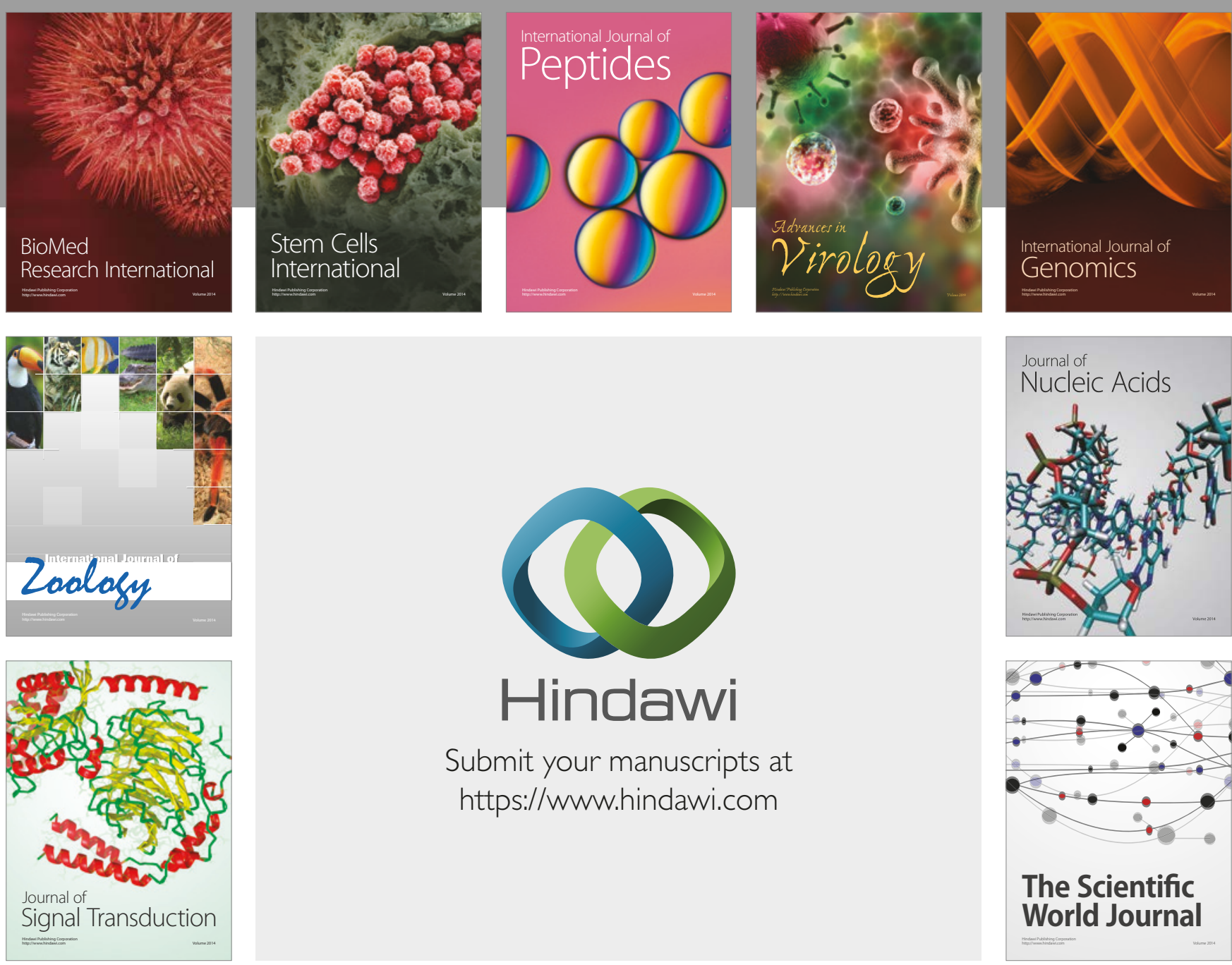

Submit your manuscripts at

https://www.hindawi.com
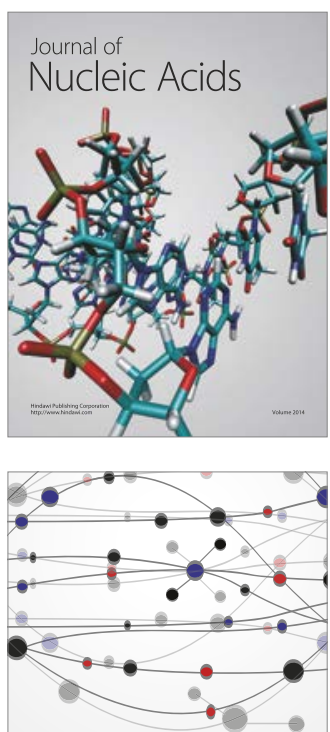

The Scientific World Journal

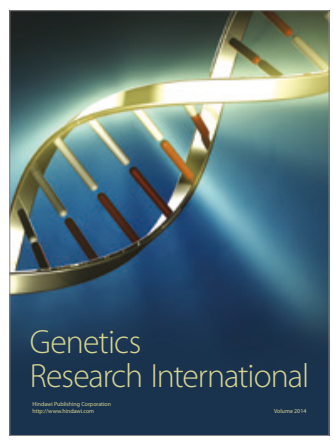

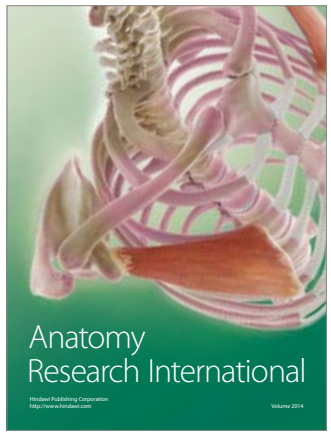

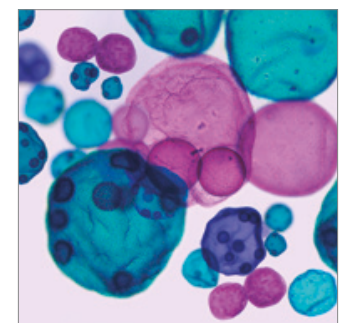

International Journal of Microbiology
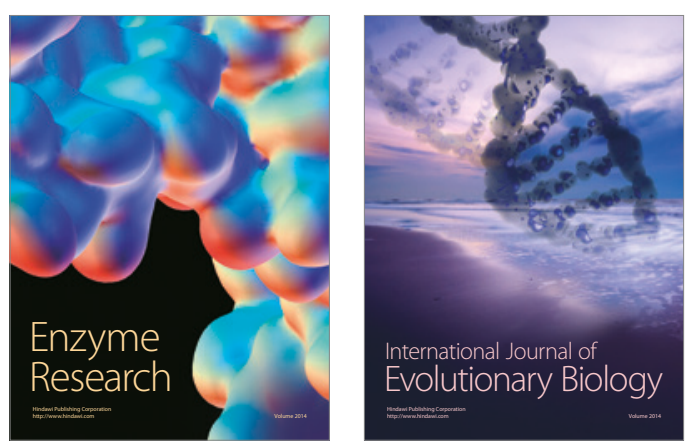
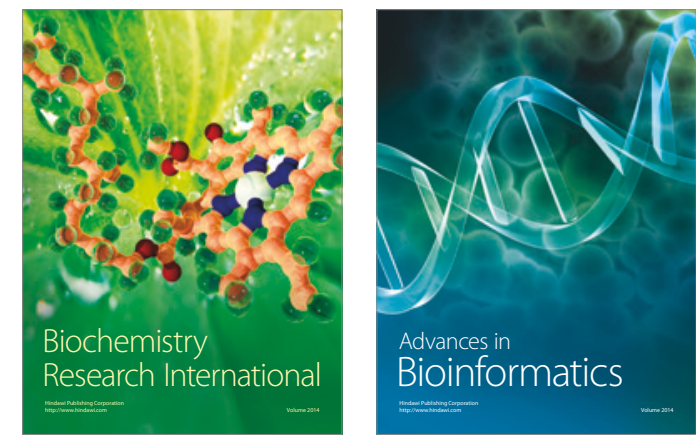

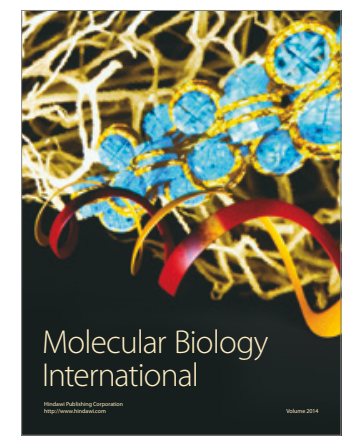

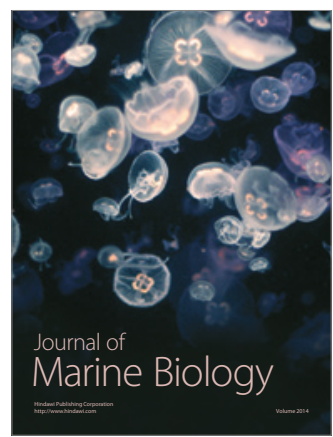

